\title{
Study of the combined effect of ammonia addition and air coflow velocity on a non-premixed methane jet flame stabilization.
}

\author{
Sophie Colson ${ }^{1,2,}{ }^{*}$, Manuel Kuhni ${ }^{1}$, Cédric Galizzi ${ }^{1}$ \\ Dany Escudié ${ }^{1}$, Hideaki Kobayashi ${ }^{3}$
}

1 Univ Lyon, CNRS, INSA-Lyon, Université Claude Bernard Lyon1, CETHIL UMR5008, F-69621, Villeurbanne, France

2 Department of Aerospace Engineering, Tohoku University, 6-6-01 Aoba, Aramaki-aza, Aoba-ku, Sendai 980-8579, Japan

${ }^{3}$ Institute of Fluid Science, Tohoku University, 2-1-1 Katahira, Aoba-ku, Sendai 9808577, Japan

* corresponding author:

sophie.colson@insa-lyon.fr

Institute of Fluid Science, Tohoku University, 2-1-1 Katahira, Aoba-ku, Sendai 9808577, Japan

(+81) $022-217-5273$

ORCID ID: https://orcid.org/0000-0001-9968-0226

\footnotetext{
* Sophie Colson: Investigation, Experiment, Analysis, Writing - original draft.

Manuel Kuhni: Supervision, Methodology, Validation.

Cédric Galizzi: Supervision, Methodology, Validation, Writing - review \& editing, Funding acquisition. Dany Escudié: Supervision, Methodology, Validation, Writing - review \& editing, Funding acquisition. Hideaki Kobayashi: Supervision, Writing - review \& editing, Funding acquisition.
} 


\title{
Study of the combined effect of ammonia addition and air coflow velocity on a non-premixed methane jet flame stabilization.
}

\begin{abstract}
Ammonia is a promising carbon-free fuel that can be used for $\mathrm{CO}_{2}$ reduction. However, ammonia industrial use presents challenges, including flame stabilization. In this study, a non-premixed methane-ammonia jet flame in an air coflow was considered to observe the effects of ammonia addition on conventional fuels flame stabilization. First, the effects of the introduction of ammonia on the stabilization regimes of the methane jet flame were studied. Then the coupled effects of the variation in ammonia concentration and air coflow velocity on flame stabilization were investigated. In the present jet configuration, a sharp reduction of the stabilization domain was observed with ammonia addition: the liftoff and re-attachment velocities were obtained for mixtures of up to $50 \%$ of ammonia in the fuel, a ratio above which the flame could not be stabilized. When increasing the coflow velocity, a sudden drop in the re-attachment velocity occurred for methane/ammonia flames. This reattachment drop was associated with an increase in the height of the lifted flame when the jet velocity decreases before re-attachment, for large enough coflow velocity and ammonia concentration. A critical height above which the lifted flames all present the same ascending behavior could be defined and characterizes this peculiar phenomenon.
\end{abstract}

Keywords: ammonia-methane mixture; non-premixed jet flame; stabilization regimes; hysteresis

\section{Nomenclature}

$C_{L}, \quad$ liftoff coefficient $\left(U_{L O} / S_{L 0}\right)$

$C_{A}, \quad$ reattachment coefficient $\left(U_{A} / S_{L O}\right)$

$D_{i}, \quad$ jet burner inner diameter

$D_{o}, \quad$ jet burner outer diameter

$e, \quad$ burner rim thickness

E, ammonia mixing ratio 
$H_{L}, \quad$ lifted flame height, i.e. distance between the burner rim and the lifted flame base $H_{T}, \quad$ jet breakpoint height

$H_{T c}$, critical jet breakpoint height corresponding to a change in the jet breakpoint evolution with the jet Reynolds number in laminar to turbulent region.

$L, \quad$ burner pipe length

$L H V_{i}$, lower heating value of species i

$Q_{d}, \quad$ diluent flow rate

$Q_{f}, \quad$ total fuel mixture (fuel + diluent) flow rate

$R e_{J}, \quad$ jet Reynolds number

$\operatorname{Re}_{J c}$, critical jet Reynolds number corresponding to the change in the jet breakpoint evolution with the jet Reynolds number in the laminar to turbulent region.

$S_{L O}, \quad$ laminar burning velocity at $\phi=1.0$

$U_{c o}, \quad$ air coflow velocity

$U_{J}, \quad$ jet velocity

$U_{L O}$, jet velocity at liftoff

$U_{A}, \quad$ jet velocity at re-attachment

$X_{i}, \quad$ mole fraction of species $i$

\section{Introduction}

Due to the concern on global warming and $\mathrm{CO}_{2}$ emissions, the use of renewable energy has been on the rise. However, the intermittency of renewable energy is a major issue (Grand et al., 2016) and the research for energy storage and transportation solutions is necessary. Among the candidate energy carriers, ammonia is promising. Indeed, it can be produced at a reasonable cost from renewable resources using water electrolysis and the Haber-Bosh process (Bicer et al., 2016; Sánchez and Martín, 2018). Other recently developed technology such as catalyst-free-plasma-based processes 
(Hawtof et al., 2019) and Samarium-Water Ammonia Production (SWAP) (Ashida et al.) also show promising perspectives for clean large-scale production of ammonia. Moreover, its transportation and storage are comparable to propane, as ammonia liquid state is observed at 9.9 atm and $25^{\circ} \mathrm{C}$, or $-33.4^{\circ} \mathrm{C}$ under atmospheric pressure (Kobayashi et al., 2019).

Ammonia is also carbon-free fuel and can be used through direct combustion for energy production with low $\mathrm{CO}_{2}$ emission. This is the so-called green ammonia concept (Kobayashi et al., 2019; Valera-Medina et al., 2018). Demonstration of gas turbine power generation (Kurata et al., 2019) are encouraging but some challenges remain for industrial usage due to NOx emission and stabilization issues. The first one has been the subject of several works, including fundamental studies on the NOx production for ammonia, methane, or their blends (Zieba et al., 2009; Li et al., 2013; Hayakawa et al., 2015), the validation of the associated chemistry (Han et al., 2019; Okafor et al., 2018; Colson et al., 2020), and practical strategies for industrial burners, such as the rich-lean strategy (Kurata et al., 2019; Okafor et al., 2019). The stabilization issue was examined for premixed ammonia/air flame by Hayakawa et al. (2017) in a swirl burner configuration, but fundamental aspects of ammonia and ammonia blend flames stabilization still need to be considered. Existing studies on ammonia or ammonia blends non-premixed jet flames remains limited (Sullivan et al., 2002; Woo et al., 2016), and mainly focus on the NOx emission issue. Deeper analysis and clarification of the ammonia blends stabilization process are thus required.

Stabilization is a key issue for industrial applications and was the subject of numerous studies. The use of a jet flame is convenient as it allows for the flame observation in a configuration that is close to applications, but also relatively simple, and readily usable to understand the physics of the stabilization phenomena. 
Stabilization of jet flames has been extensively studied (Buckmaster, 2002; Chung, 2007; Lyons, 2007; Lawn, 2009). Previous studies on non-premixed jet flames have shown that their stabilization depends strongly on the aerodynamics of the jet (Gollahalli et al., 1986; Lawn, 2009; Wyzgolik et al., 2007), but also on the shape of the jet burner (Takahashi and Schmoll, 1990; Otakeyama et al., 2009). In the present configuration, the following stabilization behavior can be observed (Lamige et al., 2014, 2013; Lamige, 2014; Min et al., 2011): when increasing the jet velocity, the flame, which is initially attached to the burner and stabilizing few millimeters away from the burner lip, lifts at a critical velocity, $U_{L O}$, and stabilizes further downstream at a distance corresponding to few times the burner outlet diameter. The lifted flame will then eventually blow out if increasing the jet velocity or will re-attach if the jet velocity is reduced. The re-attachment velocity, $U_{A}$, at which the flame gets re-attached is smaller than the liftoff velocity, $U_{L O}$, showing a characteristic hysteresis behavior first mentioned by Scholefield and Garside (1948).

Besides, the stabilization regimes and the hysteresis domain generally show dependence on the use of a coflow as noted by Takahashi and Schmoll (1990) and Leung and Wierzba (2009) and on dilution of either fuel or oxidizer (Lamige et al., 2013; Lee and Chung, 1997; Min and Baillot, 2012). The addition of ammonia to a nonpremixed methane jet flame is thus expected to impact its stabilization. The stabilization regimes of non-premixed methane jet flames with inert gas dilution were obtained in the present configuration (Min et al., 2011; Lamige et al., 2013; Marin and Baillot, 2016), and showed neglectable dependence on the air coflow velocity in the range of study. This independence, mainly attributed to burner rim thickness, was also observed by Takahashi and Schmoll (1990).

Jet lifted flames have been the subject of numbers of studies, and several theories 
and models attempted to predict their behavior, particularly their stabilization position up to blowout. They can be merged in the fully premixed model (Kalghatgi, 1983; Eickhoff et al., 1985), the leading edge model (Lawn, 2009; Lyons, 2007; Muñiz and Mungal, 1997; Han and Mungal, 2000), the extinction or scalar dissipation model, and the large eddy model (Broadwell et al., 1984), each contributing to the general understanding of flame stabilization as reviewed by Lyons (Lyons, 2007). Previous studies (Lee et al., 1994; Wu et al., 2007; Min and Baillot, 2012; Chul et al., 2012; Nada et al., 2014; Erete et al., 2017) have pointed out that the dilution of either jet or coflow has a large impact on the height at which the lifted flame stabilizes. This impact is however highly dependent on the nature of the diluent. With the gradual addition of inert diluent, lifted flames were shown to be stabilizing further downstream essentially due to the combination of pure dilution and thermal effects associated with the addition of the diluent, the chemical effect remaining minor.

Dilution with another reacting gas, like in the present study, is however different due to the nature of the gas, which is chemically active. This was illustrated in the study by $\mathrm{Wu}$ et al. (2007) where the effects of the dilution of $\mathrm{H}_{2}$ jet flame with $\mathrm{CO}_{2}$ and propane $\left(\mathrm{C}_{3} \mathrm{H}_{8}\right)$ were studied. The addition of the latter to the hydrogen jet led to a faster increase of the height at which the lifted flame stabilizes than for $\mathrm{CO}_{2}$. This difference was attributed to the drastic reduction of the laminar burning velocity when adding propane, its addition acting as a sink for $\mathrm{OH}$ and $\mathrm{H}$ radicals in the flame. It is thus essential to carefully investigate the effect of gas mixing on the stabilization process.

The purpose of this study is to clarify the effect of ammonia addition on the stabilization of a non-premixed methane jet flame in an air coflow. Stabilization regimes, and more specifically liftoff and re-attachment, were first investigated with ammonia gradual introduction. The present work thus focuses on the global characterization of 
the stabilization domain as a first approach, and local measurements were not considered, as they are particularly challenging in the present environment with ammonia addition, due to the nature of the gas, and considering how the measurement method might disturb the flame stabilization. They would nonetheless be of great interest as a development of the present work and to confront the existing stabilization theories mentioned before. The behavior of the lifted flame in the hysteresis domain and its evolution in the jet laminar-to-turbulent transition region helped was also investigated to clarify the evolution of the flame stabilization with ammonia addition.

\section{Experimental setup}

\subsection{Setup overview}

The experimental setup consists of a vertical non-premixed jet surrounded by an air coflow. It is made of a central straight pipe of $6 \mathrm{~mm}$ inner diameter, $D_{i}$, and $10 \mathrm{~mm}$ outer diameter, $D_{o}$, with a $2 \mathrm{~mm}$ burner rim thickness, $e$, from which is injected the fuel as presented in Fig.1. Pipe length, $L$, is $950 \mathrm{~mm}\left(L / D_{i}>150\right)$ and gives a fully developed velocity profile at the burner outlet, with a maximum jet velocity of $30 \mathrm{~m} / \mathrm{s}$ for methane jet. The air coflow is supplied from 4 symmetrical opposite inlets and goes through two perforated plates for relaminarization, before entering a convergent to provide a uniform velocity profile at the pipe outlet, ranging under $0.3 \mathrm{~m} / \mathrm{s}$. The jet flame is developing in a chamber of $250 \times 250 \mathrm{~mm}^{2}$ as represented in Fig. 1 preventing from outside disturbances. The chamber was designed to be large enough so that no direct interaction between the flame and the wall occurs and no large scale recirculations were observed (Lamige, 2014). The material of the pipe, and particularly its conductivity, were shown to impact the experimental results on the flame stabilization (Lamige et al., 2014), as well as on the transition between the stabilization regimes. As a first approach, the material selected in this study is common stainless 
steel (E24) with a conductivity of $54 \mathrm{~W} /(\mathrm{m} \cdot \mathrm{K})$ at $295 \mathrm{~K}$. Further details on the setup can also be found in previous works (Lamige et al., 2013; Lamige, 2014; Lamige et al., 2014).

\section{[Figure 1]}

A detailed study on the heat transfer and their evolution with ammonia addition is not presented in this work. However, most of the heat losses are expected at the burner rim for the attached flames. Their evolution with ammonia addition was the subject of a separate study focusing on burner flame interactions.

\subsection{Flow rates and mixing}

The flow rates are adjusted using thermal mass flow controllers (SLA5850 series, Brooks Instrument Co., Hatfield, PA, USA), with a precision of $0.7 \%$ of the mass flow rate, more $0.2 \%$ of the full range. Methane (purity $>99.95 \%$ ) and ammonia (purity > 99.96\%) are mixed before the injection inside the burner. Fuel mixing ratio can be expressed in different manners, such as volume or mass fraction. The heating value fraction of the fuel was selected in the present study, following the definition given in work by Okafor et al. (2018) and Ichikawa et al. (2019). The ammonia mixing ratio, $E$, is defined in Eq. (1), where $X_{i}$ is the mole fraction of the fuel $i$ and $L H V_{i}$ is the lower heating value of the specie $i$, with $L H V_{\mathrm{CH} 4}=802.3 \mathrm{~kJ} / \mathrm{kmol}$ and $L H V_{\mathrm{NH} 3}=316.8$ $\mathrm{kJ} / \mathrm{kmol}$

$$
E=\frac{X_{\mathrm{NH}_{3}} \cdot L H V_{\mathrm{NH}_{3}}}{X_{\mathrm{NH}_{3}} \cdot L H V_{\mathrm{NH}_{3}}+X_{\mathrm{CH}_{4}} \cdot L H V_{\mathrm{CH}_{4}}}
$$

Stabilization regimes were obtained by the gradual increase of the fuel flow rate for a constant value of ammonia mixing ratio, $E$, and air coflow velocity. The mean fuel jet exit velocity, $U_{J}$, and the mean air coflow velocity, $U_{c o}$, refer to the velocities 
calculated from the mass flow rates. The uncertainty in the determination of the jet velocity at liftoff and re-attachment is $2 \%$, and $3 \%$ for E. Previous laser doppler anemometry measurements (Lamige et al., 2013) were performed to characterize the present setup, and show good agreement (within $6 \%$ of error) between the mean velocity from the velocity profile measurements and the bulk velocity calculated from the mass flow rates.

\subsection{The jet structure characterization method}

To observe the jet flow variations when adding ammonia to the methane jet or varying the air coflow velocity, in both cold flow and flame configurations, the use of shadowgraph images was selected. This method allows the observation of the aerodynamics without generating disturbances contrary to sampling or seeding methods. Avoiding flow disturbances is essential in the case of the study of ammonia and ammonia blended fuels as the low reactivity of such mixtures makes the flame prompt to destabilization and sensitive to any variations in the flow field. Shadowgraph method thus allows, in this case, to get sufficient information on the jet aerodynamics, while preventing from measurement bias.

The shadowgraph images were obtained using a $5 \mathrm{~mW}$ He-Ne laser combined with a spatial filter, expanded using a lens to produce an afocal beam before going through the flame and being collected on the other side using a tracing paper screen, associated to an intensified camera with high-speed shutter for recording (PI-MAX 2, exposure time $0.2 \mathrm{~ms}$ ). The position of the flame was estimated on each image as the upstreammost position of highest intensity corresponding to the light deviation due to thermal expansion. The average lifted flame position is called lifted flame height, $H_{L}$, in the following and was obtained from 50 images of the same flame. In the same way, the average fuel jet breakpoint height, $H_{T}$, defined as in the work of Takahashi et al. (1982) 
as the point of transition to turbulence, was obtained from 50 images. Examples of shadowgraph images with $H_{T}$ and $H_{L}$ are included in the later Figs. 7 and 8. The major uncertainty in $H_{L}$ and $H_{T}$ measurement is related to the determination of the flame front or turbulence apparition on one shadowgraph image. This uncertainty is estimated to be less than 10 pixels, around $1 \mathrm{~mm}$.

\section{Results and discussion}

The results on the evolution of the stabilization regimes with ammonia addition are first introduced in the case of small air coflow velocity, $U_{c o}=0.026 \mathrm{~m} / \mathrm{s}$, close to the free-jet configuration. This small air coflow velocity case corresponds to the limit case of flame stabilization in the present confined environment. The objective of this section is first to describe the effect of ammonia addition alone on the stabilization of the jet flame. The air coflow velocity and the ratio of jet and air coflow momentum are of importance in the study of jet flames, and though the range of air coflow velocity investigated being small, its variation in the case of methane-ammonia mixtures revealed important changes in the stabilization regimes and is thus investigated. The peculiar behaviors observed could not be simply explained from the analysis of global parameters of the jet, and the re-attachment was further investigated by observation of the lifted flame height, and jet aerodynamic structure in the hysteresis domain.

\subsection{Evolution of the stabilization regimes}

\subsubsection{Effect of ammonia addition for low air coflow velocity}

The evolution with ammonia addition of the stabilization regimes of a methane non-premixed jet flame was first studied in the case of a low air coflow velocity, $U_{c o}=$ $0.026 \mathrm{~m} / \mathrm{s}$, to observe the effect of the ammonia addition alone. The fuel jet exit velocity at liftoff, $U_{J}=U_{L O}$, and re-attachment, $U_{J}=U_{A}$, are plotted with the ammonia fuel 
mixing ratio, $E$, in Fig. 2. The corresponding Reynolds numbers of the jet is $\operatorname{Re}_{J}=$ $D_{i} U_{J} / v$, where $D_{i}$ is the jet inner diameter of $6 \mathrm{~mm}$, and $v$ is the kinematic viscosity and has been calculated for each mixture using multicomponent mixture approximation as expressed by Law (2006).

[Figure 2]

Figure 2 shows that the addition of ammonia leads to both slower $U_{L O}$ and $U_{A}$, and therefore, to a reduction of the stabilization domain. The liftoff velocity, $U_{L O}$, is sharply reduced from around $16 \mathrm{~m} / \mathrm{s}$, in the case of pure methane, to less than $7 \mathrm{~m} / \mathrm{s}$ for $E=0.26$. The re-attachment velocity, $U_{\mathrm{A}}$, is also decreasing until $E=0.26$ but at a slower rate. The hysteresis domain, in between the liftoff and re-attachment is thus gradually reduced when ammonia is added as $U_{L O}$ and $U_{A}$ are getting close to each other. This region covers Reynolds number, $R e_{J}$, from 2100 to 5600 , corresponding to jets close to the transition from laminar to turbulent flow in a pipe, classically considered at $R e_{J}=$ 2300 (Schlichting, 1979), to fully turbulent jets. For $E=0.26, U_{L O}$ and $U_{A}$ become so close that an unstable flame could be observed, flame position continuously moving back and forth from the attached to the lifted position. At the end of the hysteresis domain $(E>0.26)$, where the ammonia mole fraction reaches $50 \%$ in the fuel jet, the flame cannot be stabilized on the burner anymore, leading to blowoff.

In the case of dilution by inert gas $\left(\mathrm{N}_{2}, \mathrm{Ar}, \mathrm{CO}_{2}\right)$ (Min et al., 2011; Marin and Baillot, 2016), it was found that flame was destabilized and that the liftoff occurs by the combined effects of pure dilution, thermal and chemical effect. The ratio of the flow rate of diluent, $Q_{d}$, to the fuel and diluent mixture flow rate, $Q_{f}$, at liftoff is called $\left(Q_{d} / Q_{f}\right)_{\text {lift }}$ and was shown to be a good parameter to rank the ability of the diluent in breaking the flame stability. In previous work on the same burner configuration (Marin Ospina, 2017), the largest $\left(Q_{d} / Q_{f}\right)_{\text {lift }}$ obtained for $\mathrm{Ar}, \mathrm{N}_{2}$ and $\mathrm{CO}_{2}$ dilution were 
respectively equal to $74 \%, 63 \%$, and $58 \%$, to compare to $48 \%$ in the present case for ammonia, although ammonia is a fuel, releasing heat in its combustion. The decrease in the liftoff velocity, $U_{L O}$, is thus particularly sharp in the case of ammonia addition. Contrary to the case of inert gas, where the chemical effect is expected to be moderated when compared to pure dilution or thermal effects (Marin Ospina, 2017), the chemical effect is here expected to be predominant. Radicals sink effect, due to the presence of the two fuels, and as observed in the work by Wu et al. (Wu et al., 2007) by comparing $\mathrm{CO}_{2}$ and $\mathrm{C}_{3} \mathrm{H}_{8}$ addition to a hydrogen jet flame, might be expected in the present case too, explaining the large reduction observed for ammonia addition when compared to inert gas.

The laminar burning velocity of a mixture has been shown to have a dominant impact on flame stabilization and liftoff (Lamige, 2014; Marin and Baillot, 2016). As the laminar burning velocity decreases, liftoff is expected to occur for smaller jet velocities (Marin and Baillot, 2016; Lamige et al., 2013). The position of the lifted flames also being related to the laminar burning velocity (Kalghatgi, 1983), its variation might be expected to affect the re-attachment. In a first approach to compare the evolution of the unstretched laminar burning velocity, representing flame kinetics, and the liftoff and re-attachment velocity of the mixtures investigated, the ratio $C$ of the liftoff $U_{L}$ and re-attachment $U_{A}$ velocities to the laminar burning velocity $S_{L 0}, C_{L}(=$ $\left.U_{L} / S_{L O}\right)$ and $C_{A}\left(=U_{A} / S_{L O}\right)$, respectively, have been calculated and summarized in Fig. 3. Assuming the stabilization of the non-premixed flame in near stoichiometric conditions, the laminar burning velocity obtained experimentally by Han et al. (Han et al., 2019) for stoichiometric flames were considered as a first approximation.

[Figure 3]

As noted in Fig. 3, both $C_{L}$ and $C_{A}$ ratios are varying with the ammonia mixing 
ratio, $E$. $C_{L}$ values are much larger than the $C_{A}$ ones, suggesting that the contribution of the flame chemistry and the change in the laminar burning velocity are of greater importance for the liftoff than for the re-attachment. Whereas $C_{A}$ presents a slightly increasing trend, $C_{L}$ shows a clear decrease between $E=0$ and 0.25 . The dependence on flame properties, including flame chemistry, might thus also vary with ammonia introduction, and the balance between the aerodynamic, chemical and thermal contributions change. The evolution of the stabilization regimes with ammonia addition cannot thus be simply reduced to the laminar burning velocity variations of stoichiometric flames and detailed investigation on the flame interaction with the burner will be the subject of future work to highlight how ammonia addition affects flame burner interaction up to liftoff.

Overall, both liftoff and re-attachment velocity decreased with ammonia addition and led to a particularly large reduction of the stabilization domain, especially when compared with inert diluents. For a non-neglectable part, this phenomenon might be associated with the flame combustion chemistry changes represented by the drastic decrease in the laminar burning velocity when ammonia is introduced. The relative part of these flame properties changes is however not constant, suggesting that other mechanisms should be considered to fully understand the stabilization domain reduction.

\subsubsection{The effect of the air coflow velocity on the stabilization regimes}

As mentioned in the introduction of this work, the presence of a coflow and its velocity might affect the stabilization regimes of a non-premixed jet flame and were thus investigated. The air coflow velocities were thus varied between the initial value of $U_{c o}=0.026 \mathrm{~m} / \mathrm{s}$, close to free-jet condition, and $U_{c o}=0.3 \mathrm{~m} / \mathrm{s}$. The liftoff and reattachment limits are shown in Fig. 4 where the jet Reynolds number, $R e_{J}$, corresponding to the different cases investigated (liftoff: $U_{J}=U_{L}$, re-attachment: $U_{J}=$ 
$\left.U_{A}\right)$ are plotted for various air coflow velocities, $U_{c o}$, and various mixing ratio, $E$. Whereas, similarly to the previous studies for methane flames on the same burner (Lamige, 2014), no major variations of the liftoff line were noticed, the present study shows some variations of the re-attachment line. Indeed, when the ammonia mixing ratio is increased to $E=0.15, U_{A}$ gradually decreases with higher $U_{c o}$. This dependence in the air coflow velocity coincides with the classic laminar-to-turbulent transition in pipe flow at $R e_{J}=2300$.

\section{[Figure 4] [Figure 5]}

To study more specifically the combined effect of the higher air coflow velocity with ammonia addition in the hysteresis domain, both liftoff and re-attachment velocities are plotted against $E$ for a selected air coflow velocity, $U_{c o}=0.2 \mathrm{~m} / \mathrm{s}$ in Fig. 5 .

Figure 5 shows that, for this larger air coflow velocity, the liftoff appears for lower jet velocities as ammonia is introduced, similarly to Fig. 2. However, this decrease is larger than for low air coflow velocity case and the jet Reynolds number at liftoff is reduced from 5400 for methane flames, to 630 for $E=0.3$. Another noticeable change corresponds to an evolution of the slope of the liftoff Reynolds curve close to the laminar to turbulent transition. This was mentioned in previous studies on jet and coflow dilution with inert gases (Marin and Baillot, 2016; Min et al., 2011) where lifted jet flames are mainly controlled by dilution phenomenon in the laminar range (with a large $U_{L}$ gradient relative to $E$ ), whereas for turbulent range less diluent addition is needed for destabilizing the flame, and combined aerodynamics and dilution are key to the destabilization. The stability domain, in terms of ammonia mixing ratio, $E$, is also slightly expanded with the end of the hysteresis domain, going from $E=0.26$ at $U_{c o}=0.026 \mathrm{~m} / \mathrm{s}$, to $E=0.30$ at $U_{c o}=0.2 \mathrm{~m} / \mathrm{s}$ as shown in Figs. 2 and 5 . However, as presented in Fig. 6, it can be noticed that this expansion disappears when the air coflow 
velocity keeps increasing, as in the case of $U_{c o}=0.3 \mathrm{~m} / \mathrm{s}$ with a direct blowoff at $E=$ 0.25 , and was not further studied here. Overall, the liftoff transition obtained for different ammonia mixing ratios, $E$, is only slightly affected by a variation of the air coflow velocity as shown in both Figs. 4 and 6.

[Figure 6]

Secondly, focusing now on the re-attachment line in Fig. 5, a significant difference with Fig. 2 can be noticed: a sudden drop of $U_{A}$, in terms of jet Reynolds number, $R e_{J}$, appears. This drop, called hereafter as "Re-attachment Drop" (RD) and represented by a red arrow in Fig. 5, coincides with the laminar-to-turbulent transition of the jet and significantly increases the hysteresis domain. This RD, occurring for mixtures between $E=0.15$ and $E=0.2$ at $U_{c o}=0.2 \mathrm{~m} / \mathrm{s}$ as represented in Fig. 5, is dependent on $U_{c o}$. Indeed, as seen in Fig. 6, a larger air coflow velocity leads to an RD for smaller $E$.

The relationship between the $\mathrm{RD}$, the ammonia mixing ratio, $E$, and the air coflow velocity, $U_{c o}$, is not straightforward. As ammonia is added, the jet re-attachment velocities, $U_{A}$, are becoming smaller and the relative impact of the air coflow on the jet aerodynamics and the lifted flames might be greater and should be investigated. To understand the RD origin, a more comprehensive study of the lifted flames in the hysteresis domain, and particularly of flame position in the jet, is thus necessary.

So, the study of the evolution of the stabilization regimes with ammonia addition emphasizes two particular phenomena: the drastic decrease in the stabilization domain of a methane non-premixed jet flame due to ammonia addition, but also a specific behavior, the re-attachment drop (RD), linked to combined effects of air coflow velocity and ammonia addition. As the analysis of the global characteristics of the jet flame could not satisfactorily explain the present results, the evolution of the lifted flame height in the hysteresis domain, as well as the evolution of jet structure, was further 
investigated in the next section.

\subsection{Ammonia-methane lifted flames behavior in the hysteresis domain}

To explain this singular RD, the aerodynamic of the jet and the lifted flame height in the hysteresis domain were investigated using shadowgraph imaging. The sole effect of ammonia addition is first introduced before studying the combined effect of ammonia addition and air coflow velocity to distinguish each contribution.

\subsubsection{Effect of ammonia addition for low air coflow velocity}

As ammonia is introduced in the methane jet, the thermal and diffusion properties of the mixtures are changed as introduced in Table 1. To confirm that these variations do not introduce a drastic change in the aerodynamic of the jet, the effect of ammonia addition was first viewed for a cold flow jet for $U_{c o}=0.026 \mathrm{~m} / \mathrm{s}$ at $E=0$ and 0.2 , in the jet velocity range corresponding to the hysteresis domain.

[Table 1][Figure 7]

Figure 7 shows that the jet breakpoint, $H_{T}$, normalized by the burner inner diameter, $D_{i}, H_{T} / D_{i}$, decreases for both $E$. A steep decreased of $H_{T} / D_{i}$ is noticed near the pipe flow laminar-to-turbulent transition at $\operatorname{Re}_{J}=2300$, represented by a dashed line. The jet breakpoint height, $H_{T} / D_{i}$, remains similar for the two jets in the hysteresis domain. The mechanism of the gradual reduction of the re-attachment velocity with $E$ noted in Fig. 2 cannot be explained by the variation of the jet aerodynamic alone, and the lifted flame observation is necessary.

\section{[Figure 8]}

Figure 8 displays the evolution of the lifted flame height, $H_{L}$, normalized by the burner inner diameter, $D_{i}, H_{L} / D_{i}$, within the hysteresis domain for an air coflow velocity, $U_{c o}$, of $0.026 \mathrm{~m} / \mathrm{s}$ and $E$ varying within $0-0.25$. For each $E$, the rightmost data point 
corresponds to the liftoff limit, denoted in Fig. 8 by a red contour, and the leftmost one, highlighted by black contour, corresponds to re-attachment. The hysteresis domain is represented by a grey mask. In the following, in addition to the term "lifted flame height", $H_{L}$, corresponding to the lifted flame position within the hysteresis domain, the specific position when liftoff occurs will be designated as "liftoff flame height", $H_{L O}$. The evolution of the jet breakpoint height, $H_{T}$, obtained from the shadowgraph imaging in the cold flow jet, over a wide range of $R e_{J}$, is also shown in Fig. 8.

As seen in Fig. 8, the $H_{L} / D_{i}$ increases when $E$ increases. This increase in $H_{L} / D_{i}$ is to relate to the decrease in the mixture reactivity for larger $E$ leading to lower local flame speed in the present partially premixed condition. Indeed, ammonia addition to methane flame leads to a large decrease in the laminar burning velocity (Okafor et al., 2018). Thus, and though the lifted flame being a turbulent partially premixed flame, a decrease in the edge flame propagation speed can be expected. Moreover, as discussed in the literature for inert diluents (Nada et al., 2014; Erete et al., 2017), for the same fuel jet velocity, a flame with a lower local flame speed will stabilize further downstream, where the local flow velocity is lower and can be balanced by the local flame speed. This thus leads to larger $H_{L} / D_{i}$. In the range of ammonia mixing ratio investigated, $E=0$ $-0.25, H_{L} / D_{i}$, varied between 4 and 15 in the hysteresis domain. The increase in $H_{L} / D_{i}$ is particularly pronounced for the largest $E$, with a variation between the cases $E=0.20$ and $E=0.25$, which is particularly large compared to the corresponding laminar burning velocity change assuming stoichiometric mixture condition for each $E\left(S_{L 0}=0.22 \mathrm{~m} / \mathrm{s}-\right.$ $0.21 \mathrm{~m} / \mathrm{s}$ ). For all the mixtures, the normalized lifted flame height, $H_{L} / D_{i}$, decreases from the normalized liftoff height, $H_{L O} / D_{i}$, until the re-attachment limit. This corresponds to previous observations for both non-diluted and diluted fuel nonpremixed jet flames (Kalghatgi, 1983; Chul et al., 2012; Wu et al., 2007). 
Also, and as observed in Fig. 8, it should be emphasized that the re-attachment phenomenon occurs when lifted flame height becomes almost equal to the jet breakpoint height, meaning $H_{L} / D_{i} \cong H_{T} / D_{i}$ (Scholefield and Garside, 1948). Therefore, in the case of $U_{c o}=0.026 \mathrm{~m} / \mathrm{s}$, a larger $E$ leads to a larger $H_{L} / D_{i}$, and thus, to a smaller fuel jet velocity at re-attachment, $U_{A}$, as shown in Fig. 2 . This relation at re-attachment between $H_{L} / D_{i}$ and $H_{T} / D_{i}$ should be considered for discussions of the re-attachment drop mechanism (RD) in the following sections.

\subsubsection{Effect of the air coflow velocity}

The air coflow velocity was shown to have a particularly important impact on the stabilization mechanisms of ammonia-methane jet flame, especially in the hysteresis domain as shown in Figs. 4 and 5. The aerodynamics of cold flow, upstream of the edge of the lifted flame affects, by local velocity variations and mixing variations, the edge flame propagation speed and thus the lifted flame stabilization dynamics and reattachment. To understand this effect, the jet aerodynamic is first investigated by varying the air coflow velocity from $U_{c o}=0.026 \mathrm{~m} / \mathrm{s}$, for which no RD was observed as in Fig. 2, to $U_{c o}=0.2 \mathrm{~m} / \mathrm{s}$, for which the RD is observed as in Fig. 5 .

Figure 9 shows the variations of the nondimensional jet breakpoint height of a methane jet flame $(E=0), H_{T} / D_{i}$, with the jet Reynolds number, $R e_{J}$, for two air coflow velocities, $U_{c o}=0.026 \mathrm{~m} / \mathrm{s}$ and $U_{c o}=0.2 \mathrm{~m} / \mathrm{s}$. The range of $R e_{J}$ selected covers the velocity range in the hysteresis domain as shown in Fig.4.

[Figure 9]

Similarly to observations in Fig.7, $H_{T} / D_{i}$ also decreases when the $R_{J}$ increases for $U_{c o}=0.2 \mathrm{~m} / \mathrm{s}$. In both $U_{c o}$ cases, a sudden change in the decreasing slope of $H_{T} / D_{i}$ is seen at $R e_{J}$ of 1800 to 2000 . At this point, $H_{T} / D_{i}$ controlled by laminar instabilities in the shear layer for low $R e_{J}$ is then controlled by the pipe flow transition as described by 
Takahashi et al. (1982). This critical height is called $H_{T c}$ hereafter and the corresponding Reynolds number, $R e_{J c}$. The $H_{T c} / D_{i}$ observed are between 8 and 13 for $\operatorname{Re}_{J c}$ between 1800 and 2000, depending on $U_{c o}$. They are indicated in Fig. 9 by the subscript 1 and 2 for $U_{c o}=0.026 \mathrm{~m} / \mathrm{s}$ and $U_{c o}=0.2 \mathrm{~m} / \mathrm{s}$, respectively. In the range $R e_{J}<R e_{J c}, H_{T} / D_{i}$ for $U_{c o}=0.2 \mathrm{~m} / \mathrm{s}$ is smaller than that for $U_{c o}=0.026 \mathrm{~m} / \mathrm{s}$, while above $\operatorname{Re}_{J c}, H_{T} / D_{i}$ does not depend on $U_{c o}$. The jet flow field is thus more sensitive to $U_{c o}$ for $\operatorname{Re}_{J}<\operatorname{Re}_{J c}$.

[Figure 10]

Figure 10 shows variations of the nondimensional lifted flame heights, $H_{L} / D_{i}$, with jet Reynolds number, $R e_{J}$, depending on air coflow velocity, $U_{c o}$, in the four cases of ammonia mixing ratio, $E=0,0.1,0.2$ and 0.25 . The nondimensional jet breakpoint heights, $H_{T} / D_{i}$, for $U_{c o}=0.026 \mathrm{~m} / \mathrm{s}$ and $0.2 \mathrm{~m} / \mathrm{s}$ are also indicated. For all $U_{c o}$, the rightmost data points correspond to the liftoff limit and the leftmost data points correspond to the re-attachment limit highlighted by contours in the same way as Fig.8. It can also be noticed that larger air coflow velocity, $U_{c o}$, leads to a larger $H_{L} / D_{i}$, regardless of $E$, as reviewed by Lawn (2009), showing that for higher $U_{c o}$, higher mean flow velocities are maintained further downstream in the jet leading to the larger $H_{L} / D_{i}$.

It is interesting to see that variations in the normalized lifted flame height, $H_{L} / D_{i}$, highly depend on ammonia mixing ratio, $E$. In the case of $E=0$, which means pure methane jet as shown in Fig. 10a, the $H_{L} / D i$ increase with an increase in $R e_{J}$, especially for higher $U_{c o}$. A similar tendency is seen in Fig. $10 \mathrm{~b}$ in the case of $E=0.1$. On the other hand, when $E$ is increased further, as shown in Fig. 10c for $E=0.2$ and Fig. 10d for $E=$ $0.25, H_{L} / D i$ decreases with an increase in $R e_{J}$, in the case of the higher air coflow velocity of $U_{c o}=0.1 \mathrm{~m} / \mathrm{s}$ and $0.2 \mathrm{~m} / \mathrm{s}$. As a result, $H_{L} / D_{i}$ at the re-attachment limit is larger (about 20) for high $U_{c o}$ and large $E$. In the cases of small air coflow velocity of $U_{c o}=0.026 \mathrm{~m} / \mathrm{s}$, variations of $H_{L} / D i$ with $R e_{J}$ is small regardless of $E$. 
From Fig.10, the effects of the air coflow velocity in terms of variations of $H_{L} / D_{i}$ with $R e_{J}$ depending on $E$ could be seen. Two re-attachment behaviors with decreasing $R e_{J}$ were exhibited, and their role in the mechanism of the re-attachment drop (RD) as shown in Figs. 4 and 5 is discussed in the next section.

\subsubsection{Mechanism of the re-attachment drop $(R D)$}

Two types of behaviors in the variations of $H_{L} / D_{i}, \mathrm{~A}$ and $\mathrm{B}$, are seen in Fig. 10 with the decrease in $R e_{J}$. Behavior A corresponds to the case in which $H_{L} / D_{i}$ decreases with a decrease in $R e_{J}$ and finally, the re-attachment occurs for $H_{L} / D_{i}<H_{L O} / D_{i}$. On the other hand, behavior B corresponds to the cases that $H_{L} / D_{i}$ increases with a decrease in $\operatorname{Re}_{J}$ and the re-attachment occurs for $H_{L} / D_{i}>H_{L O} / D_{i}$. In the case of low coflow velocity, $U_{c o}$ $=0.026 \mathrm{~m} / \mathrm{s}$, only behavior $\mathrm{A}$ is observed. However, for larger $U_{c o}$ both re-attachment type can be observed, depending on the value of $E$. The transition between behavior A and B for a value of $E$ corresponds to the re-attachment drop (RD) as observed in Fig. 5.

Indeed, in these higher $U_{c o}$ cases, for the smaller $E$, behavior $\mathrm{A}$ is observed and corresponds to a re-attachment for large $R e_{J}$, whereas for the higher $E$, behavior $\mathrm{B}$ is observed and the $R e_{J}$ needs to be decreased further to get the re-attachment at $H_{T} / D_{i} \cong$ $H_{L} / D_{i}$ as seen in Fig. 10. The re-attachment drop (RD) corresponds to this difference.

To explain the transition from behavior A to B, the normalized critical breakpoint height, $H_{T d} / D_{i}$, as introduced in Fig. 9, should be considered. When the lifted flame is stabilized upstream of $H_{T c} / D_{i}$, the $R e_{J}$ decrease leads to both a sharp increase of $H_{T} / D_{i}$ and a decrease of $H_{L} / D_{i}$. Finally, the flame is re-attached for $H_{T} / D_{i} \cong H_{L} / D_{i}<H_{T d} / D_{i}$, following behavior A, as seen in Fig. 10 when $U_{c o}=0.026 \mathrm{~m} / \mathrm{s}$. On the opposite, for larger $U_{c o}$, and larger $E$, higher $H_{L} / D_{i}$ are observed. Thus, when increasing $E$, the condition $H_{L} / D_{i}>H_{T d} / D_{i}$ will be satisfied and the behavior B will be obtained.

Figure 11 shows shadowgraph images for the evolution of the fuel jet and flames 
with $\operatorname{ReJ}_{\mathrm{J}}$, for $U_{c o}=0.2 \mathrm{~m} / \mathrm{s}$ and $E=0.2$, featuring behavior B as observed in Fig. 10c. The decrease in the $R e_{J}$ leads the flames to move downstream and then re-attachment occurs when $H_{T} / D_{i} \cong H_{L}, / D_{i}>H_{T d} / D_{i}$ in the region where the $H_{T} / D_{i}$ slope is lower. In those cases, for $R e_{J}>R e_{J c}$, a large flame base is developing, due to the expanded mixing region as shown in the shadowgraphs in Figs. $11 \mathrm{~b}$ and c. However, when the $R e_{J}$ is decreased under $R e_{J c}$, and the jet getting gradually laminar, mixing in this region becomes more limited as shown in Fig. 11a. Moreover, for those low $R e_{J}$, the coflow velocity becomes relatively large compared to the gradually lowered jet velocity. Based on the work by Lawn (2009), it can be understood that the flame base thus becomes narrower, as the jet span is reduced, and the flame moves upstream to stabilize where the local flow velocity is sufficiently low to be balanced by the lowered local flame speed in those lowered mixing conditions.

[Figure 11]

\subsubsection{Comparison with other fuel jets and generalization}

The behavior B, for which $H_{L} / D_{i}$ increases in the hysteresis domain with a decrease in the jet velocity, $U_{J}$, was reported by Lee et al. (1994) and Nada et al. (2014) in the case of a propane jet flame diluted with $\mathrm{N}_{2}$, as well as Terry and Lyons (2006) in an ethylene jet. Similarly to what is observed in Fig. 10 in terms of the relationship between $\operatorname{Re}_{J}$ and $H_{L} / D_{i}$, in those three studies, as the $U_{J}$ decreases, $H_{L}$ first decreases, up to a $R e_{J}$ between 2000 and 3500 , roughly corresponding to the $R e_{J c}$ observed in the present study. $H_{L}$ then reaches a minimum $H_{L m i n}$ at $U_{J}=U_{J c}$ and finally increases. $H_{L m i n} / D_{i}$, the air coflow velocity $U_{c o}$, normalized by the jet velocity $U_{J c}, U_{c o} / U_{J c}$, and the $R e_{J_{C}}$ observed in those studies are gathered in Table 2 and compared to the one obtained in the present study.

[Table 2] 
Comparing the results on propane flames diluted with nitrogen for different $U_{c o}$ by Lee et al. (1994) and Nada et al. (2014), it can be observed that $H_{L m i n} / D_{i}$ decreases as the ratio $U_{c o} / U_{J c}$ increases, similarly to the present study as seen in Fig. 10, following the trend on $H_{T c}$ shown in Fig. 9. Overall, $H_{L m i n} / D_{i}$ tends to decrease with larger $U_{c o} / U_{J c}$. Behavior B is thus expected to appear independently of the fuel used, providing that for a given mixture, $U_{c o}$ is high enough to get $H_{L}>H_{T c}$ in the laminar-to-turbulent transition of the jet.

The addition of ammonia in a methane non-premixed jet flame thus revealed the coupling effect of flame properties variations, related to the ammonia mixing ratio, and the jet aerodynamics on the flame re-attachment. Two re-attachment behaviors could be distinguished in the hysteresis domain: the behavior A, with decreasing $H_{L}$, and the behavior B with increasing $H_{L}$. The transition between $\mathrm{A}$ and $\mathrm{B}$ depends on the lifted flame height, $H_{L}$, and the structure of the jet, more particularly the critical height, $H_{T c}$, corresponding to a change in the turbulence generation. This phenomenon can be observed for other fuels, providing that their burning velocity is low enough, leading to higher $H_{L}$, or that $U_{c o}$ is high enough, leading to both higher $H_{L}$ and lower $H_{T c}$.

\section{Conclusions}

The combined effect of ammonia addition and air coflow velocity variations on the stabilization of a non-premixed methane jet flame was investigated experimentally, leading to the following conclusions:

- In the present configuration, the stabilization domain was reduced by the introduction of ammonia to methane jet. The flame could not be stabilized for ammonia mixing ratios, $E$, above 0.3 , meaning near $50 \%$ of ammonia in terms of mole fraction. Thus, the introduction of ammonia in the jet leads to a particularly 
large decrease of the liftoff velocity, especially when compared to the dilution with inert gas in previous studies, and related to the change in flame kinetics.

- For ammonia/methane jet flames, the stabilization regimes were shown to be highly dependent on the air coflow velocity, as a sudden drop of the reattachment limit was observed when the air coflow velocity is increased. This reattachment drop (RD) could be associated with the transition between two lifted flame behaviors in the hysteresis domain: the behavior A with decreasing lifted flame height, and the behavior B, with increasing lifted flame height.

- The transition between the two lifted flame behaviors and the RD is characterized by the critical jet breakpoint height, $H_{T c}$, associated with the jet aerodynamic structure and corresponding to a change in the turbulence generation within the laminar-turbulent transition. Lifted flame stabilizing under $H_{T c}$ will follow behavior A, whereas if above this height, it will follow behavior B and move downstream before re-attachment.

- The phenomenon, also observed for other fuels in the literature, is due to the coupled effects of ammonia addition and larger air coflow velocity leading to both a higher liftoff height and a smaller critical jet breakpoint height. Ammonia addition leading to a decrease in the burning velocity, and thus, a major increase of the liftoff height, the consideration of this critical jet breakpoint height, and its dependence on the air coflow velocity is expected to be of primary importance in the design of practical jet flame applications for ammonia blends use.

\section{WORD COUNTS: 6921}

Acknowledgments: This work was carried out under the Collaborative Research Project of the Institute of Fluid Science, Tohoku University, and in the framework of the Japan-France 
International Associated Laboratory (LIA) ELyT Global.

\section{References}

Ashida, Y., Arashiba, K., Nakajima, K., and Nishibayashi, Y. Molybdenum-catalysed ammonia production with samarium diiodide and alcohols or water. Nature.

Bicer, Y., Dincer, I., Zamfirescu, C., Vezina, G., and Raso, F. 2016. Comparative life cycle assessment of various ammonia production methods. J. Clean. Prod., 135, 1379.

Broadwell, J.E., Dahm, W.J.A., and Mungal, M.G. 1984. Blowout of turbulent diffusion flames. Proc. Combust. Inst., 20, 303.

Buckmaster, J. 2002. Edge-flames. Prog. Energy Combust. Sci., 28, 435.

Chul, B., Ho, S., Choi, B.C., and Chung, S.H. 2012. Autoignited laminar lifted flames of methane/hydrogen mixtures in heated coflow air. Combust. Flame, 159, 1481.

Chung, S.H. 2007. Stabilization, propagation and instability of tribrachial triple flames. Proc. Combust. Inst., 31 I, 877.

Colson, S., Hirano, Y., Hayakawa, A., Kudo, T., Kobayashi, H., Galizzi, C., and Escudié, D. 2020. Experimental and numerical study of NH3/CH4 counterflow premixed and non-premixed flames for various NH3 mixing ratios. Combust. Sci. Technol., 1.

Eickhoff, H., Lenze, B., and Leuckel, W. 1985. Experimental investigation on the stabilization mechanism of jet diffusion flames. Symp. Combust., 20, 311.

Erete, J.I., Hughes, K.J., Ma, L., Fairweather, M., Pourkashanian, M., and Williams, A. 2017. Effect of $\mathrm{CO} 2$ dilution on the structure and emissions from turbulent, nonpremixed methane-air jet flames. J. Energy Inst., 90, 191.

Gollahalli, S.R., Savaş, Ö., Huang, R.F., and Rodriquez Azara, J.L. 1986. Structure of attached and lifted gas jet flames in hysteresis region. Proc. Combust. Inst., 21, 1463.

Grand, D., Le Brun, C., Vidil, R., and Wagner, F. 2016. Electricity production by intermittent renewable sources: a synthesis of French and German studies. Eur. Phys. J. Plus, 131, 1.

Han, D., and Mungal, M.G. 2000. Observations on the transition from flame liftoff to flame blowout. Proc. Combust. Inst., 28, 537.

Han, X., Wang, Z., Costa, M., Sun, Z., He, Y., and Cen, K. 2019. Experimental and kinetic modeling study of laminar burning velocities of $\mathrm{NH} 3 /$ air, NH3/H2/air, NH3/CO/air and NH3/CH4/air premixed flames. Combust. Flame, 206, 214.

Hawtof, R., Ghosh, S., Guarr, E., Xu, C., Mohan Sankaran, R., and Renner, J.N. 2019. Catalyst-free, highly selective synthesis of ammonia from nitrogen and water by a plasma electrolytic system. Sci. Adv., 5, eaat5778. 
Hayakawa, A., Arakawa, Y., Mimoto, R., Somarathne, K.D.K.A., Kudo, T., and Kobayashi, H. 2017. Experimental investigation of stabilization and emission characteristics of ammonia/air premixed flames in a swirl combustor. Int. J. Hydrogen Energy, 42, 14010.

Hayakawa, A., Goto, T., Mimoto, R., Kudo, T., and Kobayashi, H. 2015. NO formation/reduction mechanisms of ammonia/air premixed flames at various equivalence ratios and pressures. Mech. Eng. J., 2, 14.

Ichikawa, A., Naito, Y., Hayakawa, A., Kudo, T., and Kobayashi, H. 2019. Burning velocity and flame structure of $\mathrm{CH} 4 / \mathrm{NH} 3 /$ air turbulent premixed flames at high pressure. Int. J. Hydrogen Energy, 44, 6991.

Kalghatgi, G.T. 1983. Lift-off heights and visible lengths of vertical turbulent jet diffusion flames in still air. Combust. Sci. Technol., 41, 17.

Kobayashi, H., Hayakawa, A., Somarathne, K.D.K.A., and Okafor, E.C. 2019. Science and technology of ammonia combustion. Proc. Combust. Inst., 37, 109.

Kurata, O., Iki, N., Inoue, T., Matsunuma, T., Tsujimura, T., Furutani, H., Kawano, M., Arai, K., Okafor, E.C., Hayakawa, A., and Kobayashi, H. 2019. Development of a wide range-operable, rich-lean low-NOx combustor for $\mathrm{NH} 3$ fuel gas-turbine power generation. Proc. Combust. Inst., 37, 4587.

Lamige, S. 2014. Analyse de l'Influence des Conditions aux Limites Thermiques sur la Stabilisation des Flammes Non-Prémélangées.

Lamige, S., Lyons, K.M., Galizzi, C., André, F., Kühni, M., and Escudié, D. 2014. Burner lip temperature and stabilization of a non-premixed jet flame. Exp. Therm. Fluid Sci., 56, 45.

Lamige, S., Min, J., Galizzi, C., André, F., Baillot, F., Escudié, D., and Lyons, K.M. 2013. On preheating and dilution effects in non-premixed jet flame stabilization. Combust. Flame, 160, 1102.

Law, C.K. 2006. Transport phenomena. In, Combustion Physics. Cambridge University Press, New York, 4, 141-156, pp. 141-156.

Lawn, C.J. 2009. Lifted flames on fuel jets in co-flowing air. Prog. Energy Combust. Sci., 35, 1 .

Lee, B.J., Kim, J.S., and Chung, S.H. 1994. Effect of dilution on the liftoff of nonpremixed jet flames. Symp. Combust., 25, 1175.

Lee, B.J., and Chung, S.H. 1997. Stabilization of lifted tribrachial flames in a laminar nonpremixed jet. Combust. Flame, 109, 163.

Leung, T., and Wierzba, I. 2009. The effect of co-flow stream velocity on turbulent nonpremixed jet flame stability. Proc. Combust. Inst., 32 II, 1671.

Li, B., He, Y., Li, Z., and Konnov, A.A. 2013. Measurements of NO concentration in NH3-doped $\mathrm{CH} 4+$ air flames using saturated laser-induced fluorescence and probe 
sampling. Combust. Flame, 160, 40.

Lyons, K.M. 2007. Toward an understanding of the stabilization mechanisms of lifted turbulent jet flames: Experiments. Prog. Energy Combust. Sci., 33, 211.

Marin, M., and Baillot, F. 2016. Experimental study of the lifting characteristics of the leading-edge of an attached non-premixed jet-flame: Air-side or fuel-side dilution. Combust. Flame, 171, 264.

Marin Ospina, Y.M. 2017. Etude de l'influence de la dilution du combustible et de l'oxydant dans le processus de décrochage de flammes-jet non-prémélangées et l'émission de polluants.

Min, J., and Baillot, F. 2012. Experimental investigation of the flame extinction processes of nonpremixed methane flames inside an air coflow diluted with $\mathrm{CO} 2$, N2, or Ar. Combust. Flame, 159, 3502.

Min, J., Baillot, F., Guo, H., Domingues, E., Talbaut, M., and Patte-Rouland, B. 2011. Impact of $\mathrm{CO} 2, \mathrm{~N} 2$ or Ar diluted in air on the length and lifting behavior of a laminar diffusion flame. Proc. Combust. Inst., 33, 1071.

Muñiz, L., and Mungal, M.G. 1997. Instantaneous flame-stabilization velocities in lifted-jet diffusion flames. Combust. Flame, 111, 16.

Nada, Y., Matsumoto, K., and Noda, S. 2014. Liftoff heights of turbulent non-premixed flames in co-flows diluted by CO2/N2. Combust. Flame, 161, 2890.

Okafor, E.C., Naito, Y., Colson, S., Ichikawa, A., Kudo, T., Hayakawa, A., and Kobayashi, H. 2018. Experimental and numerical study of the laminar burning velocity of $\mathrm{CH} 4-\mathrm{NH} 3-$ air premixed flames. Combust. Flame, 187, 185.

Okafor, E.C., Somarathne, K.D.K.A., Hayakawa, A., Kudo, T., Kurata, O., Iki, N., and Kobayashi, H. 2019. Towards the development of an efficient low-NOx ammonia combustor for a micro gas turbine. Proc. Combust. Inst., 37, 4597.

Otakeyama, Y., Yokomori, T., and Mizomoto, M. 2009. Stability of CH4-N2/air jet diffusion flame for various burner rim thicknesses. Proc. Combust. Inst., 32 I, 1091.

Sánchez, A., and Martín, M. 2018. Optimal renewable production of ammonia from water and air. J. Clean. Prod., 178, 325.

Schlichting, H. 1979. Boundary Layer Theory 7th ed. In Cerra, F. (Ed.) McGraw-Hill Book Company, New York.

Scholefield, D.A., and Garside, J.E. 1948. The structure and stability of diffusion flames. Symp. Combust. Flame Explos. Phenom., 3, 102.

Sullivan, N., Jensen, A., Glarborg, P., Day, M.S., Grcar, J.F., Bell, J.B., Pope, C.J., and Kee, R.J. 2002. Ammonia conversion and NOx formation in laminar coflowing nonpremixed methane-air flames. Combust. Flame, 131, 285.

Takahashi, F., Mizomoto, M., and Ikai, S. 1982. Transition from laminar to turbulent 
free jet diffusion flames. Combust. Flame, 48, 85 .

Takahashi, F., and Schmoll, W.J. 1990. Lifting criteria of jet diffusion flames. Proc. Combust. Inst., 23, 677.

Terry, S.D., and Lyons, K.M. 2006. Turbulent lifted flames in the hysteresis regime and the effects of coflow. J. Energy Resour. Technol. Trans. ASME, 128, 319.

Valera-Medina, A., Xiao, H., Owen-Jones, M., David, W.I.F., and Bowen, P.J. 2018. Ammonia for power. Prog. Energy Combust. Sci., 69, 63.

Woo, M., Choi, B.C., and Ghoniem, A.F. 2016. Experimental and numerical studies on NOxemission characteristics in laminar non-premixed jet flames of ammoniacontaining methane fuel with oxygen/nitrogen oxidizer. Energy, 114, 961.

Wu, Y., Al-Rahbi, I.S., Lu, Y., and Kalghatgi, G.T. 2007. The stability of turbulent hydrogen jet flames with carbon dioxide and propane addition. Fuel, 86, 1840.

Wyzgolik, A., Baillot, F., and Aure, F. 2007. Response of the non-premixed lifted flame to coaxial jet mixing layers. Proc. Combust. Inst., 31 I, 1583.

Zieba, M., Brink, A., Schuster, A., Hupa, M., and Scheffknecht, G. 2009. Ammonia chemistry in a flameless jet. Combust. Flame, 156, 1950. 


\section{Table List}

Table 1. Properties of ammonia/methane mixtures at $298 \mathrm{~K}$ and $1 \mathrm{~atm}$.

\begin{tabular}{|c|c|c|c|c|c|c|}
\hline $\begin{array}{c}\text { Ammonia } \\
\text { mixing } \\
\text { ratio } \\
E\end{array}$ & $\begin{array}{c}\text { Ammonia } \\
\text { mole } \\
\text { fraction } \\
\text { in the } \\
\text { fuel } \\
\text { mixture } \\
X_{N H 3}\end{array}$ & $\begin{array}{c}\text { Lower } \\
\text { heating } \\
\text { value of } \\
\text { the fuel } \\
\text { mixture } \\
\boldsymbol{L H} \boldsymbol{H} \\
{[\mathrm{kJ} / \mathrm{kmol}]}\end{array}$ & $\begin{array}{c}\text { Fuel } \\
\text { mixture } \\
\text { density } \\
\rho \\
{\left[\mathrm{kg} / \mathrm{m}^{3}\right]}\end{array}$ & $\begin{array}{c}\text { Kinematic } \\
\text { viscosity } \\
\text { of the fuel } \\
\text { mixture } \\
\boldsymbol{v} \\
{\left[\mathrm{mm}^{2} / \mathrm{s}\right]}\end{array}$ & $\begin{array}{c}\text { Thermal } \\
\text { diffusivity } \\
\text { of the fuel } \\
\text { mixture } \\
\boldsymbol{\alpha} \\
{\left[\mathrm{mm}^{2} / \mathrm{s}\right]}\end{array}$ & $\begin{array}{c}\text { Specific } \\
\text { heat } \\
\text { capacity of } \\
\text { the fuel } \\
\text { mixture } \\
\boldsymbol{C}_{\boldsymbol{p}} \\
{[\mathrm{J} /(\mathrm{kg} \cdot \mathrm{K})]}\end{array}$ \\
\hline 0 & 0 & 802.3 & 0.654 & 17.38 & 24.5 & 2225 \\
\hline 0.10 & 0.22 & 695.5 & 0.663 & 16.98 & 23.95 & 2193 \\
\hline 0.15 & 0.31 & 651.8 & 0.667 & 16.81 & 23.74 & 2179 \\
\hline 0.20 & 0.39 & 613.0 & 0.670 & 16.67 & 23.55 & 2168 \\
\hline 0.25 & 0.46 & 579.0 & 0.673 & 16.55 & 23.38 & 2158 \\
\hline
\end{tabular}

Table 2. Observations on lifted flame evolution within the hysteresis domain.

\begin{tabular}{ccccc}
\hline & $\begin{array}{c}\text { Lee } \text { et al. } \\
(\mathbf{1 9 9 4})\end{array}$ & $\begin{array}{c}\text { Nada } \text { et al. } \\
(\mathbf{2 0 1 4})\end{array}$ & $\begin{array}{c}\text { Terry and } \\
\text { Lyons (2006) }\end{array}$ & Present study \\
\hline Jet & $\mathrm{C}_{3} \mathrm{H}_{8} 62 \%$ & $\mathrm{C}_{3} \mathrm{H}_{8} 60 \%$ & Ethylene & $\mathrm{CH}_{4} / \mathrm{NH}_{3}$ \\
composition & $+\mathrm{N}_{2} 38 \%$ & $+\mathrm{N}_{2} 40 \%$ & $E=0.2,0.25$ \\
$\operatorname{Re}_{J_{c}}$ & 3500 & 2200 & 3600 & 2000 \\
$U_{c o} / U_{J_{c}}$ & 0 & 0.025 & 0.213 & $0.004-0.033$ \\
$H_{L \min } / D_{i}$ & 14 & 10 & 10 & $12-15$ \\
\hline
\end{tabular}

\section{Figure List}

Figure 1. Experimental setup.

Figure 2. Stabilization regimes with ammonia addition for $U_{c o}=0.026 \mathrm{~m} / \mathrm{s}$.

Figure 3. Variations of $C_{L}$ and $C_{A}$ with ammonia mixing ratio $E$.

Figure 4. Variations of liftoff and re-attachment limits with an increasing air coflow velocity, $U_{c o}$. The dashed line represents the pipe flow laminar-to-turbulent transition.

Figure 5. Hysteresis domain with ammonia addition for $U_{c o}=0.2 \mathrm{~m} / \mathrm{s}$. The dashed line represents the pipe flow laminar-to-turbulent transition.

Figure 6. Hysteresis domain with ammonia addition for $U_{c o}=0.026,0.1,0.2$ and 0.3 $\mathrm{m} / \mathrm{s}$.

Figure 7. Normalized jet breakpoint height, $H_{T} / D_{i}$, in the hysteresis domain for $U_{c o}=$ $0.026 \mathrm{~m} / \mathrm{s}$ in cold flow. The dashed line represents the pipe flow laminar-to-turbulent transition.

Figure 8. Lifted flame height in the hysteresis domain with ammonia addition for $U_{c o}=$ $0.026 \mathrm{~m} / \mathrm{s} . H_{T}$ for $E=0$ and cold flow.

Figure 9. Variations of jet breakpoint at $U_{c o}=0.026$ and $0.2 \mathrm{~m} / \mathrm{s}$ and $E=0$ (cold flow). 
Figure 10. Lifted flame height, $H_{L}$, in the hysteresis domain for $U_{c o}=0.026 \mathrm{~m} / \mathrm{s}, 0.1$ $\mathrm{m} / \mathrm{s}$ and $0.2 \mathrm{~m} / \mathrm{s}$ : (a) $E=0$; (b) $E=0.1$; (c) $E=0.20$ and (d) $E=0.25$.

Figure 11. Shadowgraph images of the flame in the hysteresis domain for $U_{c o}=0.2 \mathrm{~m} / \mathrm{s}$ and $E=0.20$ : (a) $\operatorname{Re}_{J}=1067$; (b) $R e_{J}=2339$; (c) $R e_{J}=2657$.

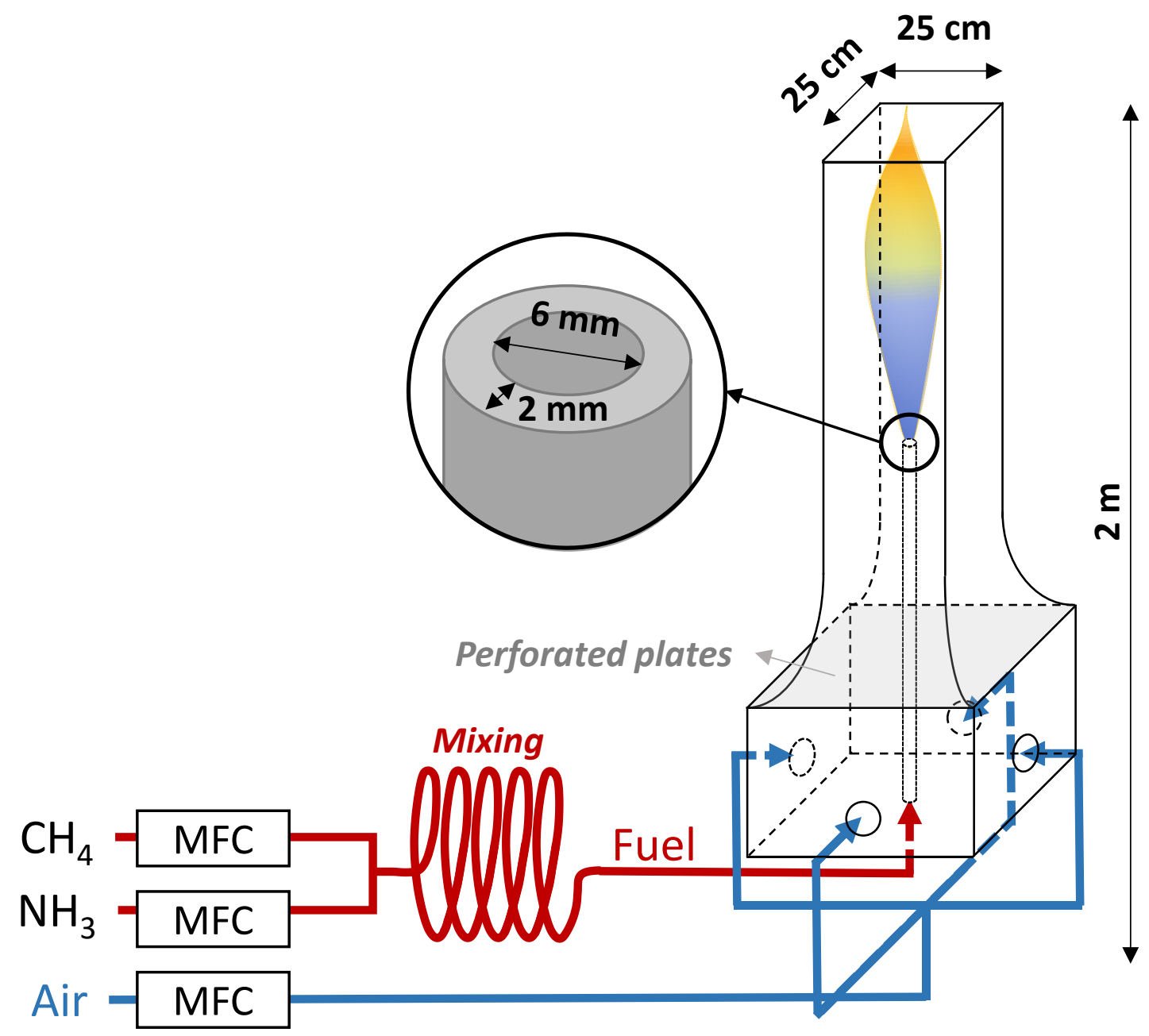

Figure 1. Experimental setup. 


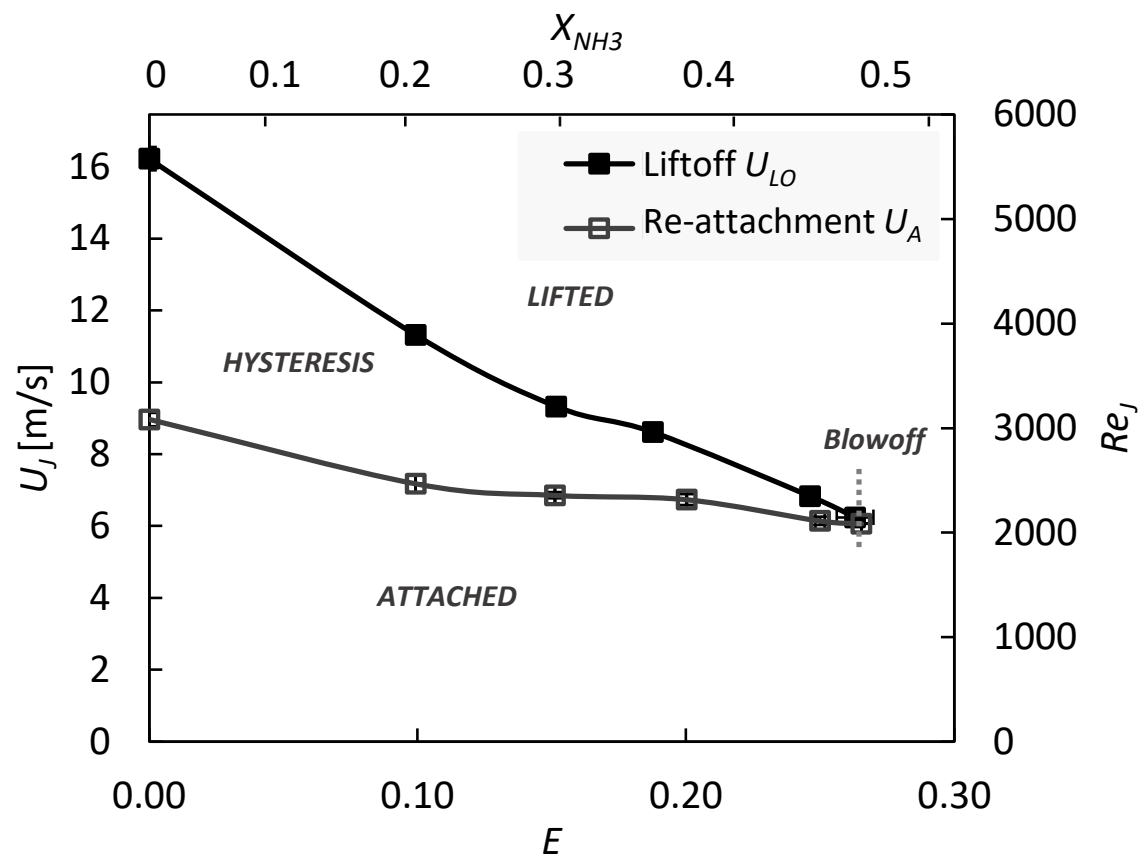

Figure 2. Stabilization regimes with ammonia addition for $U_{c o}=0.026 \mathrm{~m} / \mathrm{s}$. 


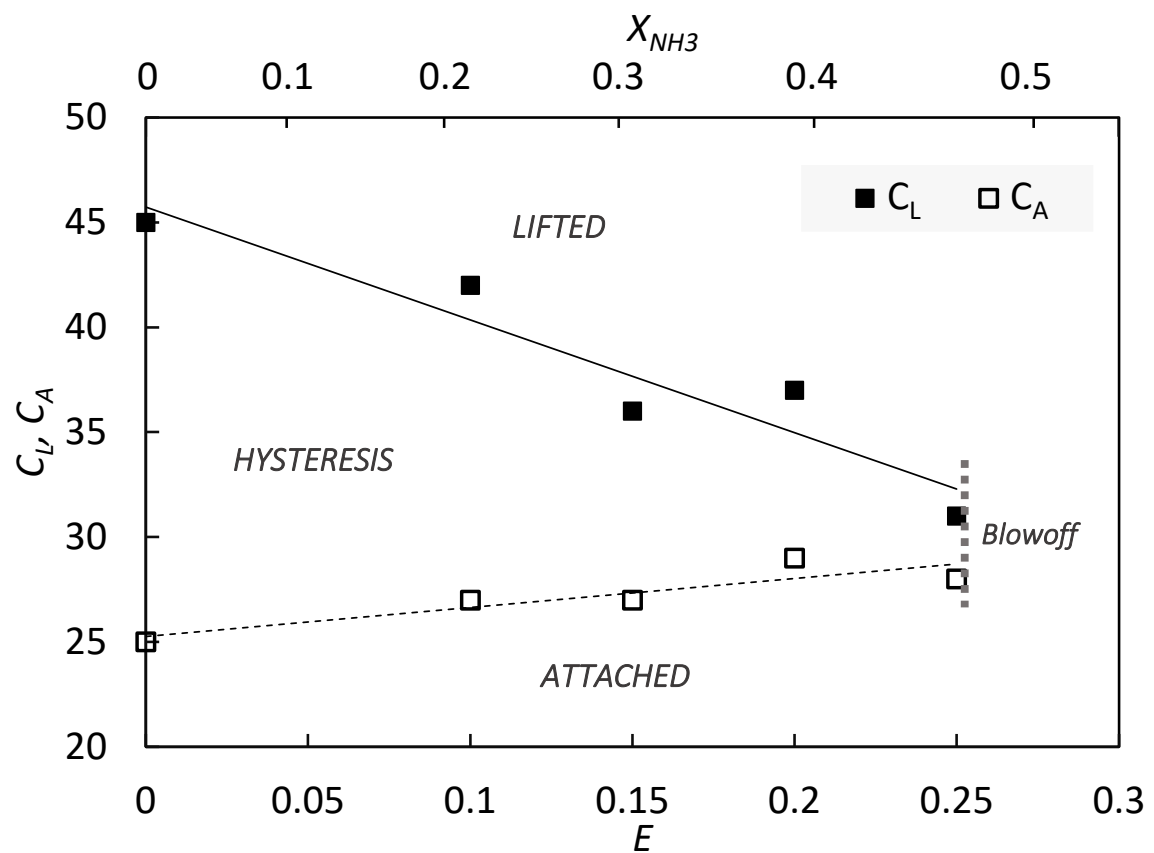

Figure 3. Variations of $C_{L}$ and $C_{A}$ with ammonia mixing ratio $E$. 


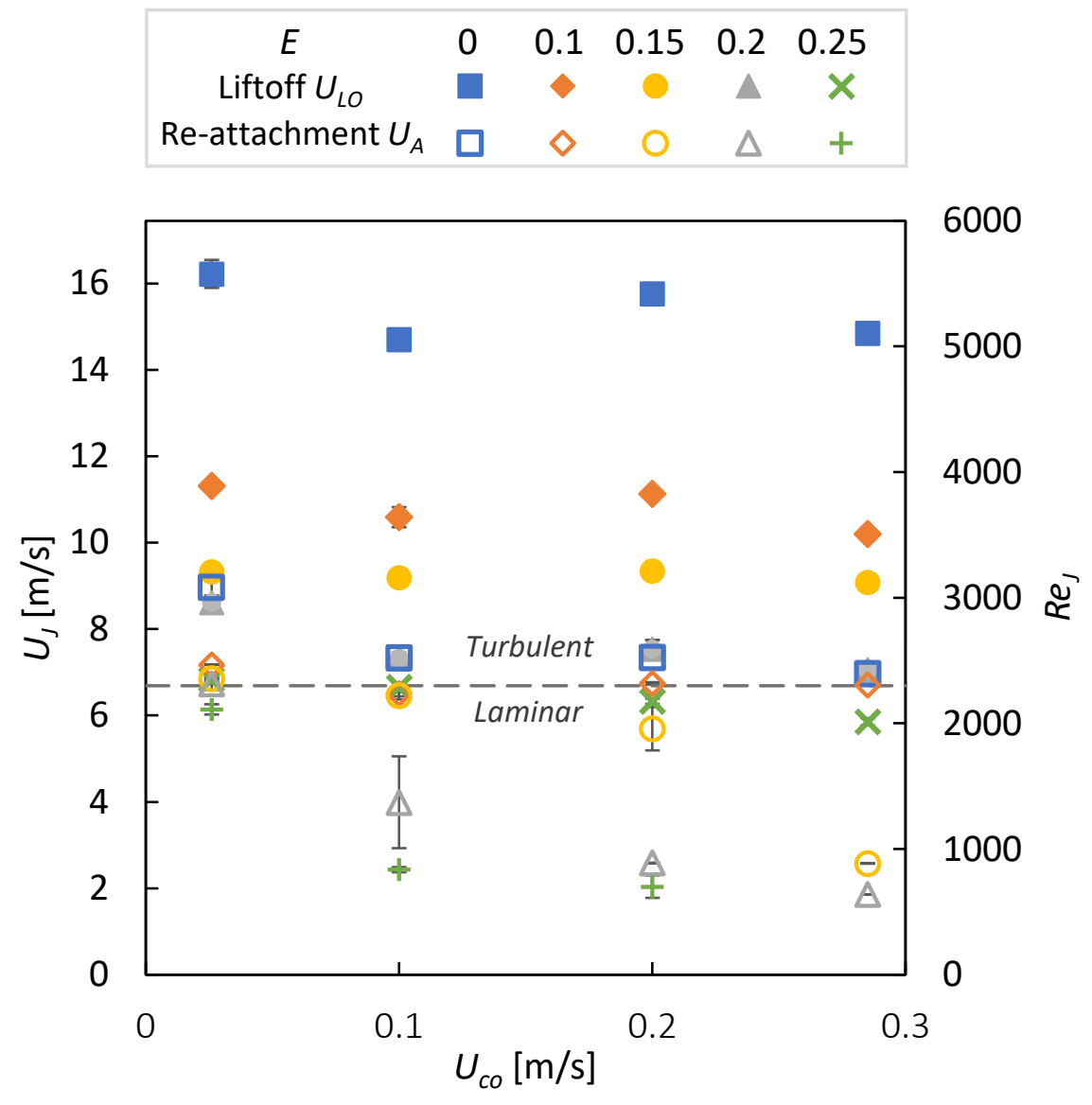

Figure 4. Variations of liftoff and re-attachment limits with an increasing air coflow velocity, $U_{c o}$. The dashed line represents the pipe flow laminar-to-turbulent transition. 


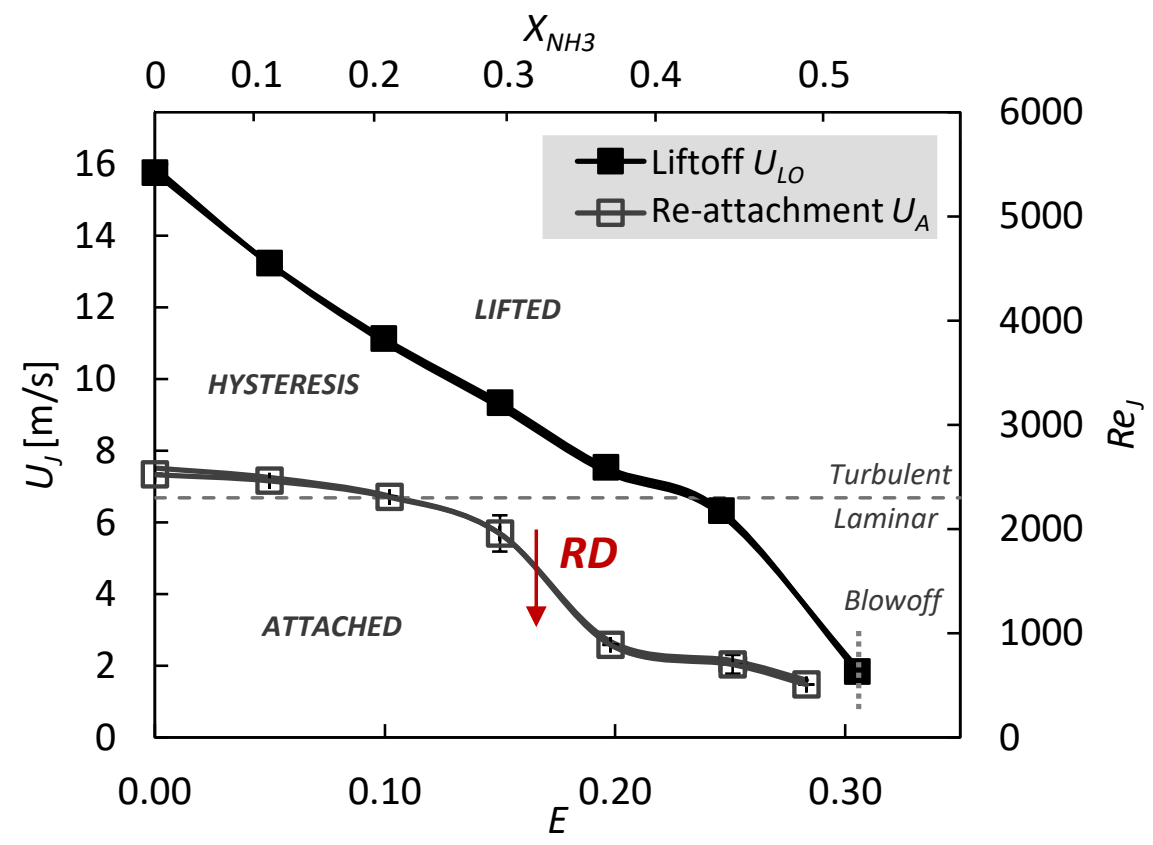

Figure 5. Hysteresis domain with ammonia addition for $U_{c o}=0.2 \mathrm{~m} / \mathrm{s}$. The dashed line represents the pipe flow laminar-to-turbulent transition. 


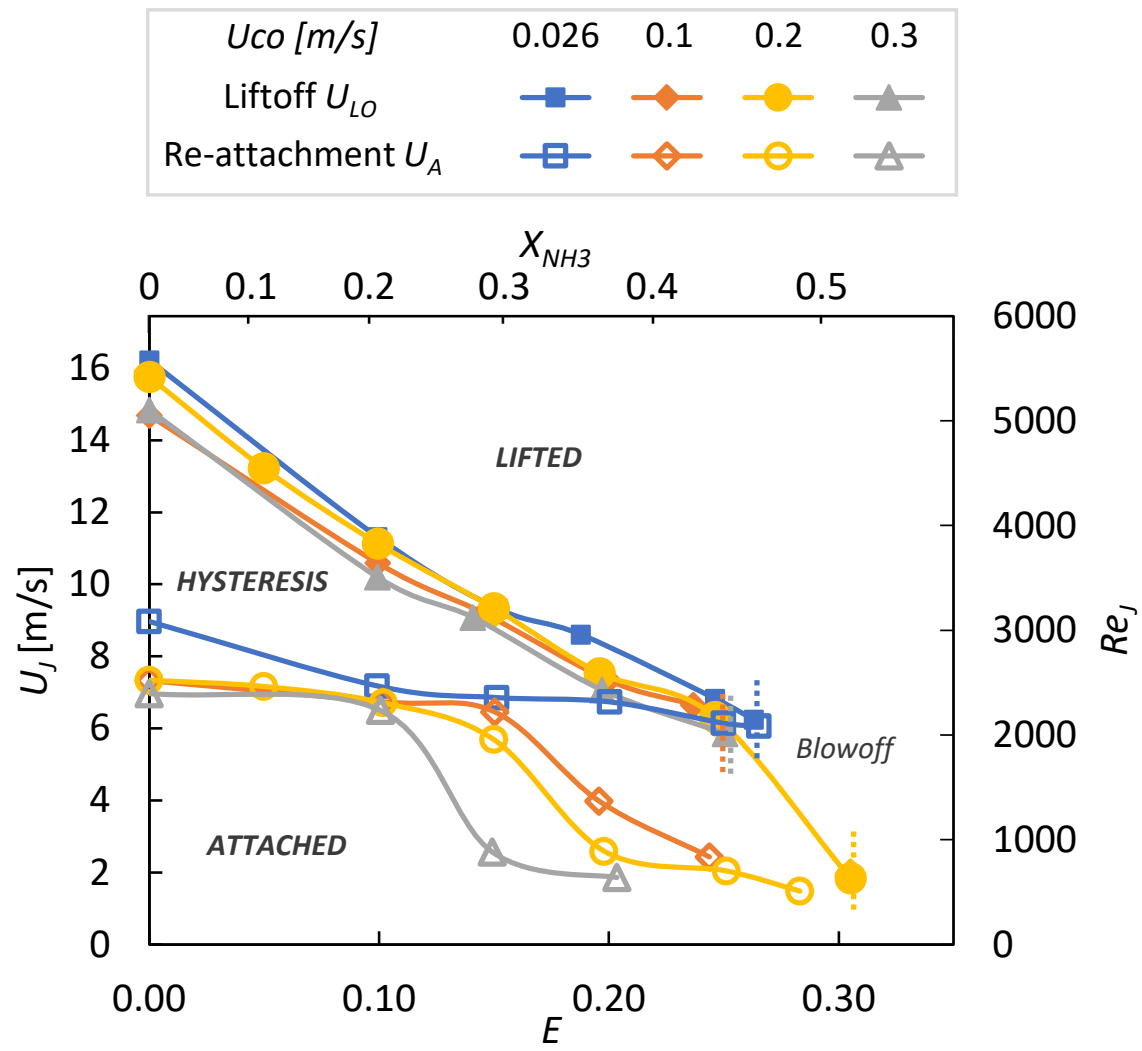

Figure 6. Hysteresis domain with ammonia addition for $U_{c o}=0.026,0.1,0.2$ and 0.3 $\mathrm{m} / \mathrm{s}$. 


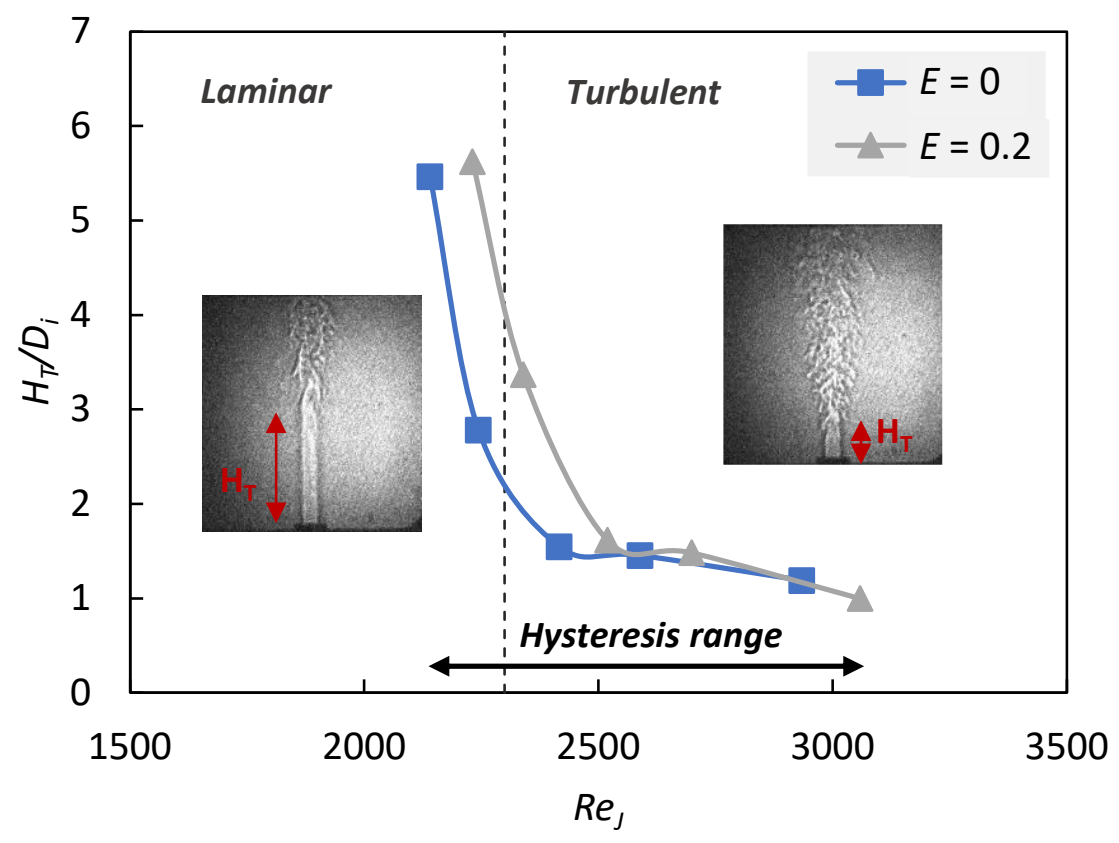

Figure 7. Normalized jet breakpoint height, $H_{T} / D_{i}$, in the hysteresis domain for $U_{c o}=$ $0.026 \mathrm{~m} / \mathrm{s}$. 


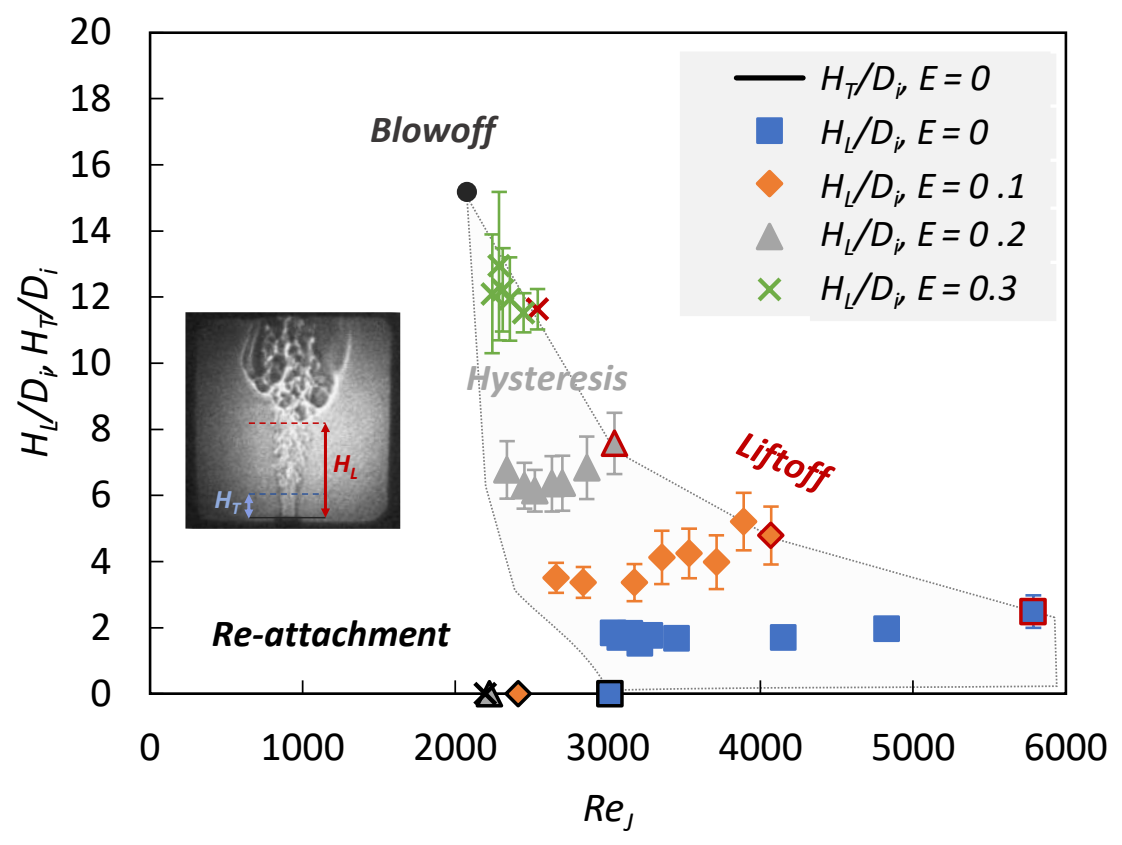

Figure 8. Lifted flame height in the hysteresis domain with ammonia addition for $U_{c o}=$ $0.026 \mathrm{~m} / \mathrm{s} . H_{T}$ for $E=0$ and cold flow. 


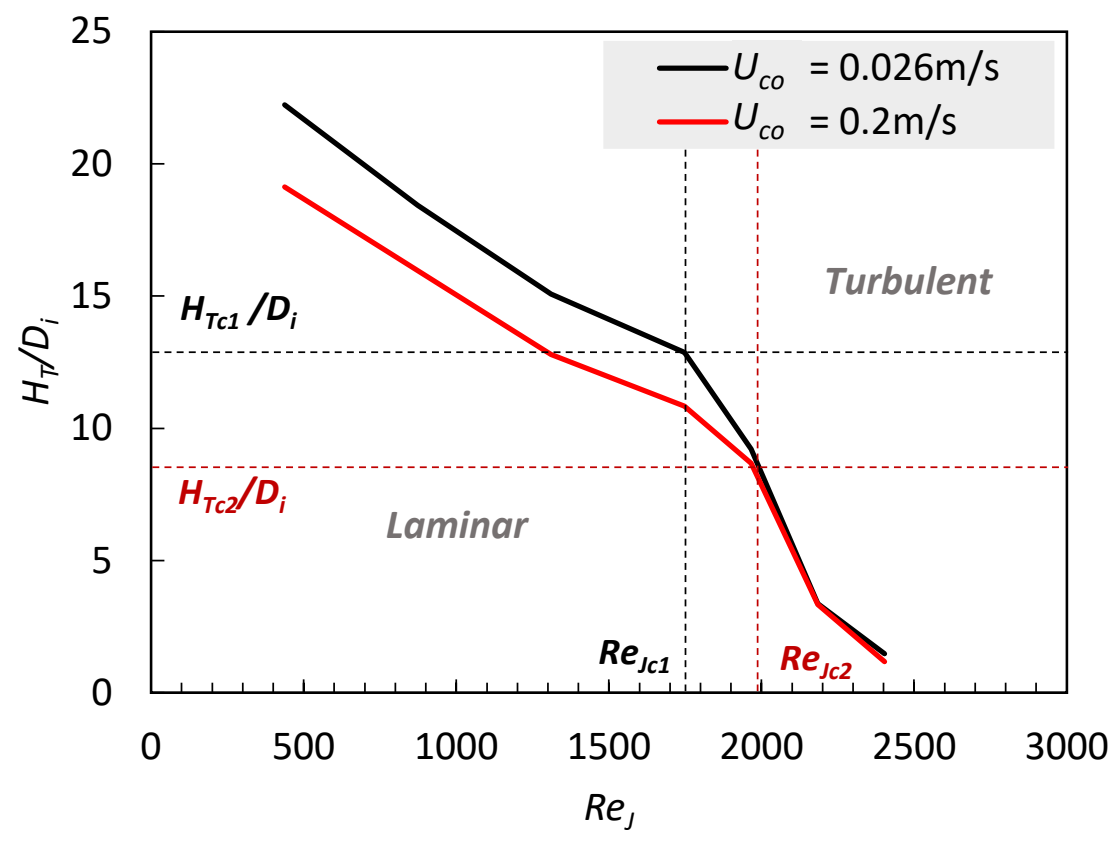

Figure 9. Variations of jet breakpoint at $U_{c o}=0.026$ and $0.2 \mathrm{~m} / \mathrm{s}$ and $E=0$ (cold flow). 

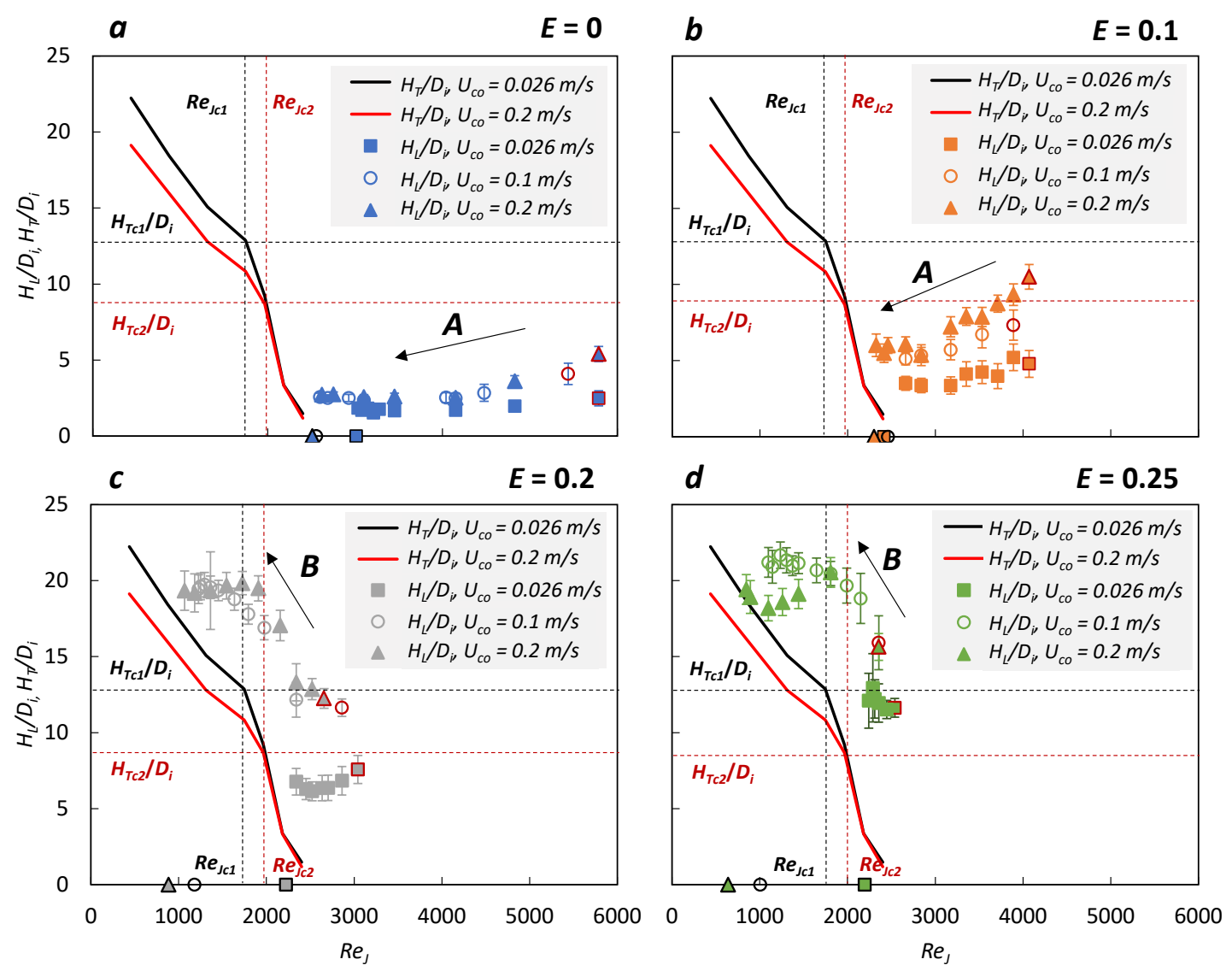

Figure 10. Lifted flame height, $H_{L}$, in the hysteresis domain for $U_{c o}=0.026 \mathrm{~m} / \mathrm{s}, 0.1$ $\mathrm{m} / \mathrm{s}$ and $0.2 \mathrm{~m} / \mathrm{s}$ : (a) $E=0$; (b) $E=0.1$; (c) $E=0.20$ and (d) $E=0.25$. 


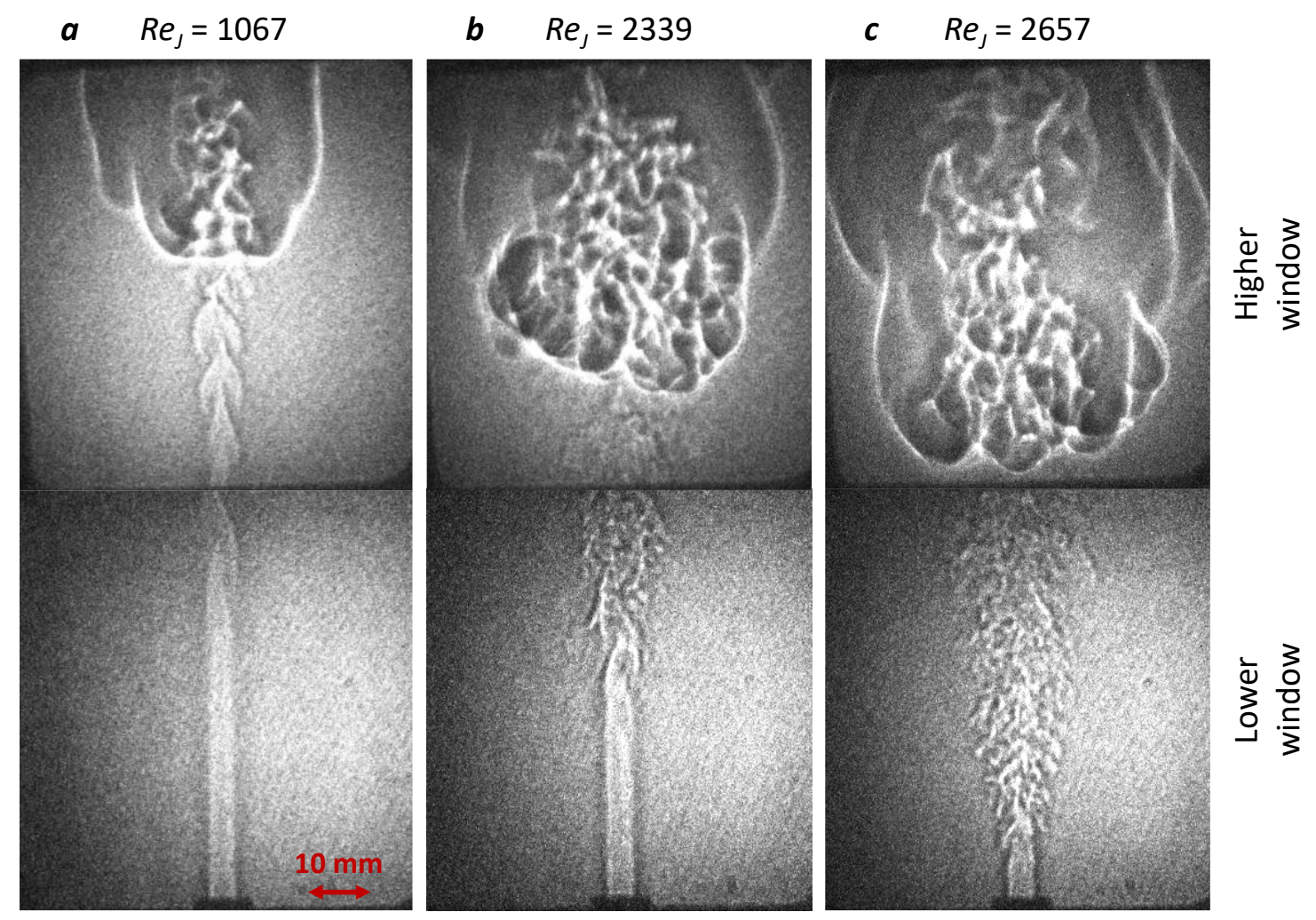

Figure 11. Shadowgraph images of the flame in the hysteresis domain for $U_{c o}=0.2 \mathrm{~m} / \mathrm{s}$ and $E=0.20$ : (a) $R e_{J}=1067$; (b) $\operatorname{Re}_{J}=2339$; (c) $R e_{J}=2657$. 